\title{
Risk factors of uterine rupture with a special interest to uterine fundal pressure
}

\author{
Sturzenegger, Karin ; Schäffer, Leonhard ; Zimmermann, Roland ; Haslinger, Christian
}

\begin{abstract}
PURPOSE Uterine rupture is a rare but serious event with a median incidence of $0.09 \%$. Previous uterine surgery is the most common risk factor. The aim of our study was to analyze retrospectively women with uterine rupture during labor and to evaluate postulated risk factors such as uterine fundal pressure (UFP). METHODS Twenty thousand one hundred and fifty-two deliveries were analyzed retrospectively. Inclusion criteria were 22 weeks and 0 days- 42 weeks and 0 days of gestation, singleton pregnancy and cephalic presentation. Women with primary cesarean section were excluded. A logistic regression analysis adjusting for possible risk factors was conducted and a subgroup analysis of women with unscarred uterus was performed. RESULTS Twenty-eight cases of uterine rupture were identified (incidence: $0.14 \%$ ). Uterine rupture was noticed in multipara patients only. In the multivariate analysis among all study patients, only previous cesarean section remained a statistically significant risk factor [adjusted odds ration (adj. OR) 12.52 confidence interval (CI) 95\% 5.21-30.09]. In the subgroup analysis among women with unscarred uterus $(n=19,415)$ three risk factors were associated with uterine rupture: UFP (adj. OR 5.22 CI 95\% 1.07-25.55), abnormal placentation (adj. OR 20.82 CI 95\% 2.48-175.16) and age at delivery $>40$ years (adj. OR 4.77 CI 95\% 1.44-15.85). CONCLUSIONS The main risk factor for uterine rupture in the whole study population is previous uterine surgery. Risk factors in women with unscarred uterus were UFP, abnormal placentation, and age at delivery $>40$ years. The only factor which can be modified is UFP. We suggest that UFP should be used with caution at least in presence of other supposed risk factors.
\end{abstract}

DOI: https://doi.org/10.1515/jpm-2016-0023

Posted at the Zurich Open Repository and Archive, University of Zurich

ZORA URL: https://doi.org/10.5167/uzh-124357

Journal Article

Published Version

Originally published at:

Sturzenegger, Karin; Schäffer, Leonhard; Zimmermann, Roland; Haslinger, Christian (2017). Risk factors of uterine rupture with a special interest to uterine fundal pressure. Journal of Perinatal Medicine, 45(3):309-313.

DOI: https://doi.org/10.1515/jpm-2016-0023 


\section{Karin Sturzenegger*, Leonhard Schäffer, Roland Zimmermann and Christian Haslinger Risk factors of uterine rupture with a special interest to uterine fundal pressure}

DOI 10.1515/jpm-2016-0023

Received January 23, 2016. Accepted April 19, 2016.

\section{Abstract}

Purpose: Uterine rupture is a rare but serious event with a median incidence of $0.09 \%$. Previous uterine surgery is the most common risk factor. The aim of our study was to analyze retrospectively women with uterine rupture during labor and to evaluate postulated risk factors such as uterine fundal pressure (UFP).

Methods: Twenty thousand one hundred and fifty-two deliveries were analyzed retrospectively. Inclusion criteria were 22 weeks and 0 days-42 weeks and 0 days of gestation, singleton pregnancy and cephalic presentation. Women with primary cesarean section were excluded. A logistic regression analysis adjusting for possible risk factors was conducted and a subgroup analysis of women with unscarred uterus was performed.

Results: Twenty-eight cases of uterine rupture were identified (incidence: $0.14 \%$ ). Uterine rupture was noticed in multipara patients only. In the multivariate analysis among all study patients, only previous cesarean section remained a statistically significant risk factor [adjusted odds ration (adj. OR) 12.52 confidence interval (CI) 95\% 5.21-30.09]. In the subgroup analysis among women with unscarred uterus $(n=19,415)$ three risk factors were associated with uterine rupture: UFP (adj. OR 5.22 CI 95\% 1.07-25.55), abnormal placentation (adj. OR 20.82 CI 95\% 2.48-175.16) and age at delivery > 40 years (adj. OR 4.77 CI 95\% 1.44-15.85).

Conclusions: The main risk factor for uterine rupture in the whole study population is previous uterine surgery. Risk factors in women with unscarred uterus were UFP, abnormal placentation, and age at delivery $>40$ years. The only factor which can be modified is UFP. We suggest that UFP should be used with caution at least in presence of other supposed risk factors.

*Corresponding author: Karin Sturzenegger, MD, Division of Obstetrics, University Hospital of Zürich, Frauenklinikstrasse 10, 8091 Zürich, Switzerland, Tel.: 0041-76-222-3886, Fax: 0041-255-44-48, E-mail: karin.sturzenegger@usz.ch Leonhard Schäffer, Roland Zimmermann and Christian Haslinger: Division of Obstetrics, University Hospital of Zürich, Frauenklinikstrasse 10, 8091 Zürich, Switzerland
Keywords: Abnormal placentation; maternal age; multiparity; uterine fundal pressure; uterine rupture.

\section{Introduction}

Uterine rupture is a serious, life-threatening event with a high risk of maternal and fetal morbidity and mortality. Several risk factors have been identified, the most important being a uterine scar, mostly from previous cesarean section [1-3]. The median incidence of uterine rupture based on studies in high-income countries is around $0.09 \%$ [3]. After previous cesarean section, the incidence varies between $0.4 \%$ and $0.9 \%[3,5]$ whereas in women without prior uterine surgery the incidence of uterine rupture is about $0.006 \%-0.02 \%$ [4, 5]. In addition to previous cesarean section, postulated risk factors for uterine rupture are induction of labor, maternal age, multiparity, gestational age at delivery, vacuum-assisted birth, fetal birth weight, short inter pregnancy interval, prolonged second stage of labor, abnormal placentation, and uterine fundal pressure (UFP) [2, 6-15]. Although UFP is widely used [16] - a survey in the US found that in $80 \%$ of institutions UFP was applied [17] - there is scarce data about its' association with uterine rupture [16, 17]. UFP involves the application of manual pressure on the uppermost part of the uterus, directed towards the birth canal in an attempt to shorten the second stage of labor [16]. Thereby, the intrauterine pressure in the second stage of labor transiently increases by up to $86 \%$ [18], which might pose a relevant factor in the pathophysiology of uterine rupture.

The aim of our study was to perform a retrospective analysis of women with uterine rupture during labor and to evaluate postulated, less studied risk factors such as UFP. UFP so far was not studied in a sufficiently powered study population with an appropriate statistical analysis that includes the adjustment for other possible risk factors in a multivariate regression.

\section{Materials and methods}

A retrospective cohort study at the University hospital of Zürich was directed by obtaining data from our electronic database Perinat. 
This database is a local comprehensive electronic health record containing all diagnoses and parametriced detailed clinical data about the course of pregnancy, delivery, maternal and infant outcome. The study has ethical affirmation according to the Institutional Review Bord decision for the use of anonymized patient data for medical research (January 2000-December 2013), based on the World Medical Association Declaration of Helsinki. All deliveries between January 2000 and December 2013 were included. Twenty thousand one hundrd and fifty-two deliveries fulfilled the inclusion criteria ( $\geq 22$ weeks and 0 days of gestation, singleton pregnancy, cephalic presentation). The exclusion criteria were primary cesarean section, breech presentation, multiple pregnancy, and incomplete documentation. Information about the following obstetric parameters was collected: maternal age, parity, gestational age at delivery, post term pregnancy, previous uterine surgery, mode of delivery, use of UFP, medical induction of labor, duration of second stage of labor, abnormal placentation (placenta increta, accreta or percreta), and fetal birth weight. Previous uterine surgery was defined as surgery involving the uterine wall and the mucosa of the uterus, in most cases due to cesarean section. To identify patients with uterine rupture and exclude patients with uterine dehiscence only, surgery reports of all suspected cases of uterine rupture were studied. Uterine rupture was determined as a full-thickness disruption of the uterine wall that also involves the overlying visceral peritoneum (uterine serosa). Statistical analysis was performed using Sigmaplot 12.0 (Systat Software Inc., CA, USA). The incidence of risk factors for uterine rupture and baseline characteristics in patients with and without uterine rupture were compared using the $z$-test. The level of statistical significance was set at $\mathrm{P}<0.05$. A multivariate logistic regression analysis adjusting for the postulated risk factors for uterine rupture (maternal age, post term pregnancy, previous uterine surgery, vacuum assisted delivery, use of UFP, medical induction of labor, duration of second stage of labor, abnormal placentation, and fetal birth weight) was conducted. In a second step, a subgroup analysis of women with scarred and unscarred uterus was performed.

\section{Results}

Twenty thousand one hundrd and fifty-two deliveries at the University hospital of Zürich between January 2000 and December 2013 were examined. Seventeen thousand nine hundred and fifty-seven vaginal births (89.1\%) were observed, from 13,787 spontaneous vaginal deliveries, 1225 vaginal deliveries with UFP, 2723 vacuum-assisted deliveries and 222 vacuum-assisted deliveries with UFP. Two thousand one hundred and ninety-five women had a secondary cesarean section (10.9\%). Twenty-eight cases of uterine rupture were identified $(0.14 \%$ of the observed population). Out of these, 22 women had a cesarean section during labor and six a vaginal birth with postpartum diagnosis of uterine rupture. Among these six women with uterine rupture during vaginal birth, one had a spontaneous delivery, three a vacuum-assisted delivery, and UFP was applied in two women (Figure 1). All patients with uterine rupture were multipara while in patients without uterine rupture multiparity was seen in $51.5 \%(\mathrm{P}=0.01)$ (Table 1). Of the patients with uterine rupture $53.6 \%$ had prior surgery compared to $3.6 \%$ of patients without uterine rupture $(\mathrm{P}<0.01)$. Five patients $(17.9 \%)$ with uterine rupture were over 40 years old at time of delivery compared to $5.9 \%$ in the group without uterine rupture $(\mathrm{P}=0.02)$. Another statistically significant difference was found in patients with induction of labor and previous uterine surgery: in the group of women with uterine rupture, $14.3 \%$ of patients had this combination of risk factors compared to only $0.6 \%$ of patients in the

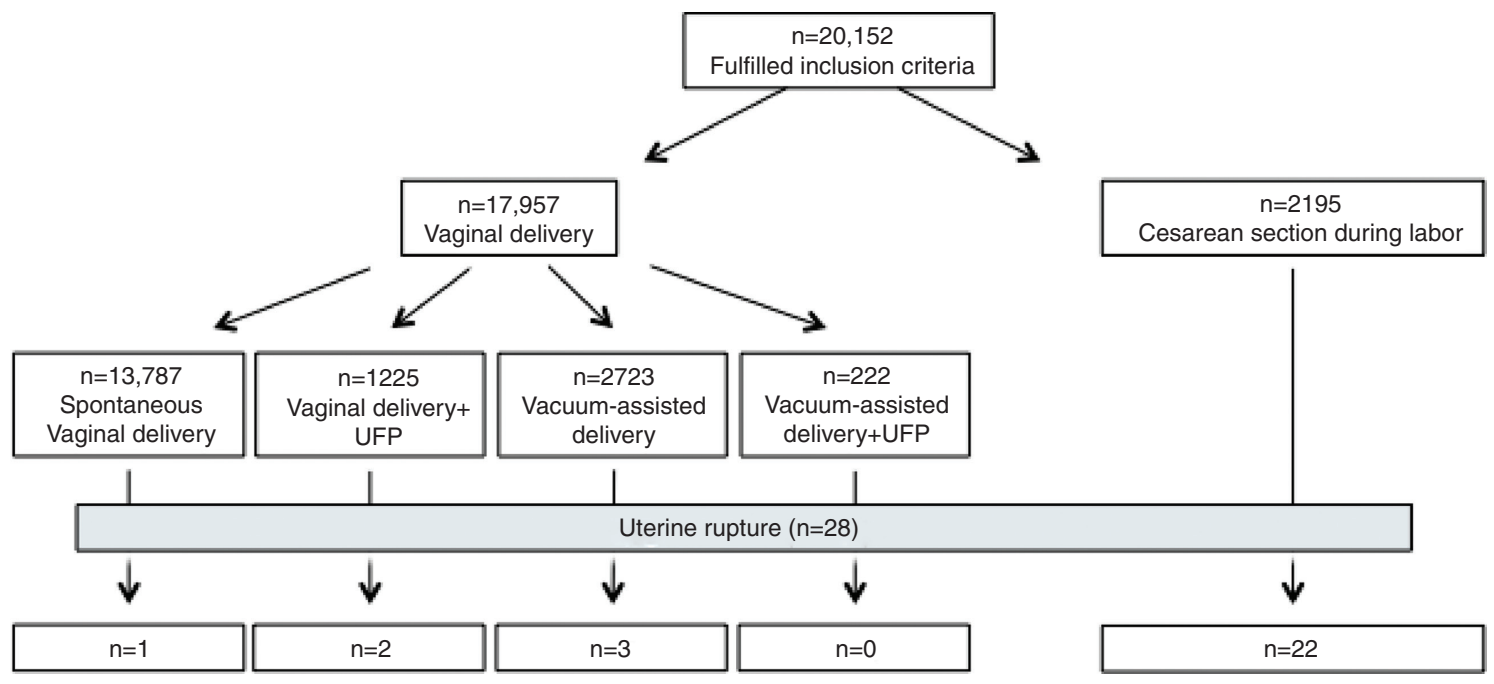

Figure 1: Occurrence of uterine rupture according to birth mode. UFP=Uterine fundal pressure. 
Table 1: Incidence of risk factors for uterine rupture and baseline characteristics in patients with and without uterine rupture.

\begin{tabular}{|c|c|c|c|c|}
\hline & With uterine rupture $(\mathrm{n}=28)$ & Without uterine rupture $(n=20,124)$ & Total $(n=20,152)$ & P-value \\
\hline Secondary cesarean ${ }^{\mathrm{a}}$ & $78.6 \%(22)$ & $10.8 \%(2173)$ & $11 \%(2195)$ & $<0.001$ \\
\hline Vaginal birth with fundal pressure & $7.1 \%(2)$ & $6.0 \%(1223)$ & $6 \%(1225)$ & 0.818 \\
\hline Vacuum assisted delivery & $10.7 \%(3)$ & $13.5 \%(2720)$ & $13.5 \%(2723)$ & 0.876 \\
\hline Previous uterine surgery ${ }^{\mathrm{a}}$ & $53.6 \%(15)$ & $3.6 \%(722)$ & $3.7 \%(737)$ & $<0.001$ \\
\hline Maternal age $\geq 40$ years $^{\mathrm{a}}$ & $17.9 \%(5)$ & $5.9 \%(1189)$ & $5.9 \%(1194)$ & 0.022 \\
\hline Multiparity ${ }^{\mathrm{a}}$ & $100 \%(28)$ & $51.5 \%(10358)$ & $51.5 \%(10386)$ & $<0.001$ \\
\hline Medical induction of labor & $25.0 \%(7)$ & $19.8 \%(3974)$ & $19.8 \%(3981)$ & 0.651 \\
\hline Induction of labor+scarred uterus $\mathrm{s}^{\mathrm{a}}$ & $14.3 \%(4)$ & $0.6 \%(128)$ & $0.7 \%(132)$ & $<0.001$ \\
\hline $2^{\text {nd }}$ stage of labor $\geq 120 \mathrm{~min}$ & $3.6 \%(1)$ & $15.8 \%(3181)$ & $15.8 \%(3182)$ & 0.131 \\
\hline Birth weight $>4 \mathrm{~kg}$ & $3.6 \%(1)$ & $8.5 \%(1709)$ & $8.5 \%(1710)$ & 0.555 \\
\hline Abnormal placentation & $3.6 \%(1)$ & $0.3 \%(65)$ & $0.3 \%(66)$ & 0.147 \\
\hline Gestational age $\geq 40$ weeks & $32.1 \%(9)$ & $43.9 \%(8839)$ & $43.9 \%(8848)$ & 0.286 \\
\hline
\end{tabular}

Data are expressed as \% UFP=Uterine fundal pressure. Risk factors indicated by superscript 'a' mean significant result. Values highlighted in bold also indicate significant result.

group of patients without uterine rupture $(\mathrm{P}<0.01)$. There was no statistically significant difference regarding other investigated risk factors such as abnormal placentation, protracted second stage of labor, birth weight over $4 \mathrm{~kg}$, and post-term pregnancies (Table 1). In the multivariate regression analysis, only previous uterine surgery was associated with uterine rupture (adj. OR 12.52, CI: 95\% 5.21-30.09). Further explored risk factors (UFP, vacuumassisted birth, multiparity, induction of labor, induction of labor in patients with previous uterine surgery, age $>40$ years, prolonged second stage of labor $>2 \mathrm{~h}$, postterm pregnancy, abnormal placentation, infants' birth weights $>4 \mathrm{~kg}$ ) did not result in a statistically significant association (Table 2). In a second step, a subgroup analysis was performed and patients with or without previous uterine surgery were analysed separately. The analysis of the subgroup of women with previous uterine surgery $(n=737)$ did not show any further association of another risk factor with uterine rupture. In the subgroup of women with unscarred uterus $(n=19,415)$, three risk factors were associated with the occurrence of uterine rupture: abnormal placentation (adj. OR 20.82 CI 95\% 2.48-175.16), application of UFP (adj. OR 5.22 CI 95\% 1.07-25.55) and age at delivery over 40 years (adj. OR 4.77 CI 95\% 1.44-15.85) (Table 3). These findings remained when only multipara patients were analyzed (data not shown).

\section{Discussion}

The overall incidence of uterine rupture was $0.14 \%$ (28 of 20,152) which is higher than the median incidence of uterine rupture based on studies in high-income countries $(0.09 \%)$ [3]. This finding may be related to the thorough assessment of a single center-database. Rupture in patients with previous uterine surgery was seen in 2.04\% (15 of 737), compared to $0.9 \%-1 \%$ in other large retrospective studies [3,20]. Also in the subgroup of women with an unscarred uterus, in our collective a higher incidence of uterine rupture was observed as compared to the published incidence in other studies $(0.067 \%$ vs. $0.02 \%-0.006 \%$ ) [3-5]. The results in our study population allow three main conclusions: firstly and in accordance to many other publications, we found that the main risk factor for uterine rupture is previous uterine surgery [3, 19, 21]. Secondly, uterine rupture was found in multipara patients only. Thirdly, in our subgroup analysis of women with unscarred uterus, three risk factors were associated with uterine rupture: UFP, abnormal placentation and maternal age $\geq 40$ years. Apart from previous uterine surgery as an accepted main risk factor in the literature, there is less consent about other possible risk factors. Many studies investigate only few possible risk factors without performing a multivariate logistic regression analysis $[7,19]$. It is methodologically disputable to postulate a risk factor for uterine rupture without adjustment for previous uterine surgery. Kaczmarczyk published solid data using accurately a logistic regression model for the identification of risk factors for uterine rupture [3]. However, the influence of UFP was not evaluated. Therefore, we conducted a multivariate analysis that included the factor UFP $[3,13,21]$. Use of UFP is only indicated in case of complications such as prolonged second stage of labor, which represents another risk factor for uterine rupture itself [13]. Adjustment for this possible confounder is inevitable in a risk evaluation. In our study population, women with unscarred uterus had a five-fold risk for uterine rupture after use of UFP. This finding is even more important, as UFP is widely used although there is scarce data about its safety $[12,16,17]$. We further confirm risk factors such 
Table 2: Adjusted odds ratios for uterine rupture.

\begin{tabular}{lrrr}
\hline & Adj. odds ratio & CI 95\% & P-value \\
\hline Vaginal birth with uterine fundal pressure & 2.46 & $0.56-10.85$ & 0.234 \\
Vacuum assisted delivery & 1.45 & $0.35-5.95$ & 0.604 \\
Maternal age $\geq 40$ years & 1.43 & $0.48-4.24$ & 0.524 \\
Abnormal placentation & 4.87 & $0.57-41.73$ & 0.149 \\
Gestational age $\geq 40$ weeks & 1.03 & $0.41-2.56$ & 0.951 \\
Medical induction of labor & 1.28 & $0.35-4.66$ & 0.712 \\
Second stage of labor $\geq 120$ min & 1.17 & $0.29-4.79$ & 0.825 \\
Birth weight $>4$ kg & 1.00 & $0.99-1.00$ & 0.027 \\
Previous uterine surgery & $\mathbf{1 2 . 5 1}$ & $\mathbf{5 . 2 1 - 3 0 . 0 1}$ & \\
Induction of labor and scarred uterus & 1.54 & $0.27-8.96$ & 0.001 \\
\hline
\end{tabular}

$\mathrm{Cl}=$ Confidence interval. Values highlighted in bold indicate significant result.

Table 3: Adjusted odds ratios for uterine rupture in women with unscarred uterus.

\begin{tabular}{lrrr}
\hline & Adj. odds ratio & Cl 95\% & P-value \\
\hline Vaginal birth with uterine fundal pressure & 5.22 & $\mathbf{1 . 0 7 - 2 5 . 5 5}$ & $\mathbf{0 . 0 4 1}$ \\
Vacuum assisted delivery & 2.65 & $0.47-14.99$ & 0.263 \\
Maternal age $\geq 40$ years & 4.77 & $\mathbf{1 . 4 4 - 1 5 . 8 5}$ & $\mathbf{0 . 0 1 0}$ \\
Abnormal placentation & $\mathbf{2 0 . 8 2}$ & $\mathbf{2 . 4 8 - 1 7 5 . 1 6}$ & $\mathbf{0 . 0 0 5}$ \\
Gestational age $\geq 40$ weeks & 0.60 & $0.18-2.00$ & 0.408 \\
Medical induction of labor & 0.96 & $0.26-3.61$ & 0.948 \\
Second stage of labor $\geq 120$ min & 4.15 & $0.95-18.25$ & 0.058 \\
Birth weight $>4$ kg & 0.73 & $0.09-5.93$ & 0.769 \\
\hline
\end{tabular}

$\mathrm{Cl}=$ Confidence interval. Values highlighted in bold indicate significant result.

as abnormal placentation and increased maternal age as already described [22]. Induction of labor is postulated as important risk factor by many other authors, although this conclusion was not supported by all published studies [3, $4,23,24]$. In our study population, induction of labor in patients with previous uterine surgery seemed to be associated with uterine rupture $(\mathrm{P}<0.01)$. Interestingly, after logistic regression in a multivariate analysis, the adjusted odds ratio missed the level of statistical significance. A strength of our study is the adequate number of women with a standardized management during delivery. Our electronic database allows solid documentation of the requested information, which is filled in prospectively. Documentation is completed for every patient before discharge and supervised by the attending consultant. Hence, the database allows a reliable retrospective analysis. A multivariate logistic regression analysis adjusting for the postulated risk factors for uterine rupture was conducted, in opposition to many other studies [3, 13, 21]. The rarity of uterine rupture may result in a statistical inaccuracy in any single center study like ours. Wide 95\% confidence intervals shall be expected in this situation. A large number of patients would be required to minimize the bias of different cofactors. Nevertheless, studies based on a multicenter or nationwide database may imply inaccuracy due to a varying quality level of documentation. It is known that especially the documentation and associated peripartal outcome after use of UFP is reported rather unreliably [17]. As a clinical consequence of our data, UFP should be used with caution. Previous uterine surgery, multiparity, abnormal placentation, and maternal age $\geq 40$ years are pre-existing risk factors of the parturient woman. According to our results, the only parameter which can be modified with regard to uterine rupture, is UFP. We suggest that UFP should be avoided at least in presence of other supposed risk factors.

\section{Compliance with ethical standards}

Disclosure of potential conflicts of interest: The authors declare that they have no conflict of interest.

Research involving human participants and/or animals: For this type of study formal consent is not required. This article does not contain any studies with human participants or animals performed by any of the authors. The study has ethical affirmation according to the Institutional Review Bord decision for the use of anonymised patient data for medical research (January 2000-December 2013), based on the World Medical Association Declaration of Helsinki. 


\section{References}

[1] Landon MB, Spong CY, Thom E, Hauth JC, Bloom SL, Varner MW, et al. Risk of uterine rupture with a trial of labor in women with multiple and single prior cesarean delivery. Obstet Gynecol. 2006;108:12-20.

[2] Kwee A, Bots ML, Visser GHA, Bruinse HW. Obstetric management and outcome of pregnancy in women with a history of caesarean section in the Netherlands. Eur J Obstet Gynecol Reprod Biol. 2007;132:171-6.

[3] Kaczmarczyk M, Sparén P, Terry P, Cnattingius S. Risk factors for uterine rupture and neonatal consequences of uterine rupture: a population-based study of successive pregnancies in Sweden. Br J Obstet Gynaecol. 2007;114:1208-14.

[4] Guise JM, McDonagh MS, Osterweil P, Nygren P, Chan BKS, Helfand $M$. Systematic review of the incidence and consequences of uterine rupture in women with previous caesarean section. Br Med J. 2004;329:19-25.

[5] Porreco RP, Clark SL, Belfort MA, Dildy GA, Meyers JA. The changing specter of uterine rupture. Am J Obstet Gynecol. 2009;200:269.e1-4.

[6] Taylor LK, Simpson JM, Roberts CL, Olive EC, Henderson-Smart DJ. Risk of complications in a second pregnancy following caesarean section in the first pregnancy: a population-based study. Med J Aust. 2005;183:515-9.

[7] Kieser KE, Baskett TF. A 10-year population-based study of uterine rupture. Obstet Gynecol. 2002;100:749-53.

[8] Ofir K, Sheiner E, Levy A, Katz M, Mazor M. Uterine rupture: risk factors and pregnancy outcome. Am J Obstet Gynecol. 2003;189:1042-6.

[9] Ofir K, Sheiner E, Levy A, Katz M, Mazor M. Uterine rupture: differences between a scarred and an unscarred uterus. Am J Obstet Gynecol. 2004;191:425-9.

[10] Rageth JC, Juzi C, Grossenbacher H. Delivery after previous cesarean: a risk evaluation. Swiss Working Group of Obstetric and Gynecologic Institutions. Obstet Gynecol. 1999;93:332-7.

[11] Moiety FMS, Azzam AZ. Fundal pressure during the second stage of labor in a tertiary obstetric center: a prospective analysis: fundal pressure during labor. J Obstet Gynaecol Res. 2014;40:946-53.

[12] Matsuo K, Shiki Y, Yamasaki M, Shimoya K. Use of uterine fundal pressure maneuver at vaginal delivery and risk of severe perineal laceration. Arch Gynecol Obstet. 2009;280:781-6.

[13] Sakr R, Berkane N, Barranger E, Dubernard G, Daraï E, Uzan S. Unscarred uterine rupture-case report and literature review. Clin Exp Obstet Gynecol. 2007;34:190-2.

[14] Walsh CA, Baxi LV. Rupture of the primigravid uterus: a review of the literature. Obstet Gynecol Surv. 2007;62:327-34; quiz 353-4.

[15] LeMaire WJ, Louisy C, Dalessandri K, Muschenheim F. Placenta percreta with spontaneous rupture of an unscarred uterus in the second trimester. Obstet Gynecol. 2001;98(5 Pt 2):927-9.

[16] Api O, Balcin ME, Ugurel V, Api M, Turan C, Unal O. The effect of uterine fundal pressure on the duration of the second stage of labor: a randomized controlled trial. Acta Obstet Gynecol Scand. 2009;88:320-4.

[17] Verheijen EC, Raven JH, Hofmeyr GJ. Fundal pressure during the second stage of labour. Cochrane Database Syst Rev. 2009:CD006067. DOI: 10.1002/14651858.CD006067.pub2.

[18] Buhimschi CS, Buhimschi IA, Malinow AM, Kopelman JN, Weiner CP. The effect of fundal pressure manoeuvre on intrauterine pressure in the second stage of labour. $\mathrm{Br} J$ Obstet Gynaecol. 2002;109:520-6.

[19] Hofmeyr GJ, Say L, Gülmezoglu AM. WHO systematic review of maternal mortality and morbidity: the prevalence of uterine rupture. Br J Obstet Gynaecol. 2005;112:1221-8.

[20] Murphy DJ. Uterine rupture. Curr Opin Obstet Gynecol. 2006;18:135-40.

[21] Zwart JJ, Richters JM, Ory F, de Vries JIP, Bloemenkamp KWM, van Roosmalen J. Uterine rupture in The Netherlands: a nationwide population-based cohort study. Br J Obstet Gynaecol. 2009;116:1069-78; discussion 1078-80.

[22] Miller DA, Goodwin TM, Gherman RB, Paul RH. Intrapartum rupture of the unscarred uterus. Obstet Gynecol. 1997;89(5 Pt 1):671-3.

[23] Flamm BL, Anton D, Goings JR, Newman J. Prostaglandin E2 for cervical ripening: a multicenter study of patients with prior cesarean delivery. Am J Perinatol. 1997;14:157-60.

[24] Grossetti E, Vardon D, Creveuil C, Herlicoviez M, Dreyfus M. Rupture of the scarred uterus. Acta Obstet Gynecol Scand. 2007;86:572-8.

The authors stated that there are no conflicts of interest regarding the publication of this article. 